\title{
Exploring Motivational and Learning Differences With Mature Students in Post-Secondary Education
}

\author{
William C. Murray, Leslie Smith, \& Keith Nielson \\ New Brunswick Community College
}

This study examines the differences that exist among various age cohorts attending a post-secondary educational institution. Respondents were from the New Brunswick Community College's six separate campuses $(n=251)$. Significant differences were found to exist predominantly around social and family issues. Although differences did appear based on age groupings, a small amount of variation appeared when compared with theoretical literature. The largest barrier to post-secondary education that existed, regardless of age, was the financial burden placed upon the learner.

\section{Introduction}

$T$ he authors of this study, as educators and students respectively in post-secondary education, shine a light on the motivational and learning needs of mature students in the community college system. In classrooms across the country, there is a visible shift in the age of students returning to study, noted experientially by the authors and within the national media (Tamburri, 2009). When coupled with a reduced number of younger students, related directly to lower birth rates over the last 20 years, educators are facing new challenges when developing and managing the learning environment.

The motivational issues among student groups gains more salience when the increase in the number of mature students returning to college for retraining is blended with a continually shrinking pool of younger students. This research seeks to unpack some of the motivational and learning differences that exist for mature students, results that may very well transfer throughout post-secondary educational systems. As Lowy (2007) stated, "the flip side of every dilemma is the opportunity for insight" (p. 86). Although the differences among age cohorts may present a dilemma for educations, there is also a great opportunity to learn and adapt.

\section{Changing Student Demographics}

Post-secondary education continues to be an attractive option for people searching for employment, whether 
a new job or a better job. This is reinforced by James Knight, President of the Association of Canadian Community Colleges: "a college diploma or applied degree is a ticket to a job” (Tamburri, 2009). The training supplied by colleges, when combined with recognized credentials, is a very attractive combination to those who are without work. The attraction is drawing older students seeking skill upgrading and retraining, changing the face of learners in post-secondary education throughout North America. In fact, mature students are enrolling at a faster rate than the traditional high school target audience (Tamburri, 2009).

The change in demographics of our learners brings into question many of the traditional assumptions made by educators of students in higher education programs. As learners ourselves, the authors have firsthand experiences with the changing educational pressures faced by different age cohorts. Research has been done that theoretically explores both internal and external factors influencing the learning experience of different student age-cohorts (Bamber \& Tett, 2000; O’Donnell \& Tobbell, 2007). O'Donnell and Tobbell (2007) reinforce the differences by age group of learners, specifically around varying career experiences, family situations, and prior educational experiences.

Additionally, for the mature or "non-traditional" student group, the learning environment may seem alien and may require a larger amount of negotiated change to the external environment. Bamber and Tett's (2000) work highlights that non-traditional students hold a very different disposition towards their learning, with a stronger focus on practical skill outcomes as they progress through their professional upgrading. These sentiments are reinforced by Lundberg (2003) who suggests adult student performance is benefited by strong social relationships and they overcome barriers using improved time management skills acquired through life experiences.

\section{Project Development}

The genesis of this study came from two complement- ary streams of interest by the author team. As part of his college studies in 2008, Nielson led a group of his peers in a marketing research assignment to satisfy the requirements of course work in his program of study. As a mature student himself, Nielson noted obvious behavioural differences between younger and more mature students within his own class on a daily basis. From this, Nielson adapted his marketing/consumer behaviour project in an effort to gain a better understanding of the dynamics among age clusters within his own management class. At the same time, Smith was crafting a theoretical paper on mature learners within higher education, exploring key cohort differences in learning motivations and styles. These two streams were blended together by Murray as the framework for a large quantitative study on motivational issues and barriers in the postsecondary system.

\section{Studying the Students}

The original questionnaire developed by Nielson for his class work served as the starting point for this research, from which the authors expanded upon the variety of questions for consideration. It was at this point that the authors were reminded of the contention that a "camel is a horse designed by a committee;" the list of questions became unwieldy due to the various directions of the authors, creating a challenge in limiting the number of questions. Fortunately, a large and validated study had been completed just three years earlier (Kimmel \& McNeese, 2006) focusing on motivational issues of adult learners. ${ }^{1}$ As Kimmel had centred her analysis specifically on gender and ethnicity variances, she generously agreed to supply her original survey instrument for our study rooted in age-based differences.

From this, the authors refocused their questions around three key themes: motivators, barriers, and attitudes and values. All questions were measured on a 5-point Likert scale. Many questions focused specifically on the learning environment; how-

\footnotetext{
${ }^{1}$ Due to the size limitations for submissions to Collected Essays on Learning and Teaching, a copy of the questionnaire used could not be included. Contact for additional information should be made to the primary author.
} 
ever, some questions clearly explored the personal domains of students, including family pressures and career goals. Age groupings were adopted from prior studies conducted within the New Brunswick Community College's (NBCC) system on academic readiness in order to facilitate future data comparison across studies.

The Chief Learning Officer of NBCC granted the authors both ethics approval and permission to contact all students at the six English campuses via the student email system. This allowed the authors to take a census approach, contacting all registered students simultaneously, a population in 2009 that slightly exceeded 3,500 students according to campus registrars.

\section{Highlighting the Differences}

Two hundred and fifty-one completed surveys were received over the seven day collection period for a response rate just below $7 \%$ over all six campuses. It is not uncommon for students within this population to be lax in regularly checking their college email accounts, a limit to this collection method. However, the responses received varied well among groupings, with $53 \%$ of respondents under the age of $25,14 \%$ between the ages of 25 and 29, and the remaining $33 \%$ of respondents 30 years of age or older. Aggregated results from the Likert scale ratings were analyzed by ranking means via SPSS V14 to identify preferences in each of the four established themes. MANOVA testing was completed to establish statis- tically significant differences for each question by age grouping. Although a number of variations between age groups emerged, no more than $25 \%$ of questions in any topic area revealed differences; a number of these are investigated below.

\section{Motivations}

From the results provided for all 15 motivation-based questions, only five showed any significant difference among age groups as indicated in Table 1. From this data, we realized that external factors, specifically around family stage, had a significant influence on the desire to pursue higher education. Younger students were much more influenced by encouragement from teachers and mentors $(\mathrm{F}=6.612 ; \mathrm{p}<0.01)$, while more mature students drew on encouragement from their spouses $(\mathrm{F}=10.664 ; \mathrm{p}<0.001)$ and children $(\mathrm{F}=39.128$; $\mathrm{p}<0.001)$; younger students have fewer spouses and children, while older students have moved beyond the influences of their teachers. This indicates that each age cohort draws on specific contextual influencers in their decision making process.

Additionally, we were able to demonstrate that the desire to begin a new career was significantly different among age groups $(\mathrm{F}=3.393 ; \mathrm{p}<0.05)$. This feeling jumped significantly from respondents in the youngest group to those in the middle age group $(\mathrm{p}<0.001)$, indicating an increased focus on career related issues as age rises. This is a curious result, indicating the students in their late twenties are at a critical career juncture and perhaps have not yet experienced a satisfying career experience. Further investigation into this facet through focus groups or

\section{Table 1}

Motivational Rankings (means with ranking level in parenthesis)

\begin{tabular}{|l|c|c|c|c|}
\hline & Aggregated & 24 and younger & 25 to 29 & 30 and older \\
\hline Desire to begin a new career & $4.50(3)$ & $4.22(3)$ & $4.77(1)$ & $4.43(2)$ \\
\hline Encouragement from my spouse & $2.51(8)$ & $1.98(10)$ & $3.47(5)$ & $2.99(8)$ \\
\hline Encouragement from my teacher/mentor & $2.33(9)$ & $2.73(8)$ & $2.07(10)$ & $1.78(12)$ \\
\hline Desire to be a role model for my children & $2.11(10)$ & $1.26(12)$ & $2.50(9)$ & $3.35(5)$ \\
\hline Encouragement from my children & $1.38(13)$ & $0.64(15)$ & $1.10(15)$ & $2.75(10)$ \\
\hline
\end{tabular}


in-depth interviews may reveal additional insight.

\section{Barriers}

Reflective of prior theoretical studies, Table 2 shows there to be a stronger barrier for more mature learners with concern to time spent away from their families $(\mathrm{F}=6.349 ; \mathrm{p}<0.01)$. Students older than 24 years of age demonstrated greater concern ( $\mathrm{p}<0.01)$, logically correlating to the fact that this group will have a higher percentage of both spouses and children. This external factor is not a barrier of importance with traditional younger learners.

One fascinating attitude difference that emerged was the comfort level learners had attending classes with students younger than themselves $(\mathrm{F}=30.394 ; \mathrm{p}<0.001)$. The oldest age cohort held the strongest concern about attending classes with younger students $(\mathrm{p}<0.001)$, ranking it as their fourth highest barrier issue, above concerns about their own personal abilities. From this, instructors need to be cognizant of comfort levels among agebased cohorts and perhaps dedicate resources towards group integration activities.

\section{Attitudes and values}

The area encompassing attitudes and values that learners hold towards their higher education did reveal a few fascinating differences as shown in Table 3. Firstly, the different age cohorts expressed differences in contentment with instructors teaching to them $(\mathrm{F}=11.028 ; \mathrm{p}<0.001)$. The youngest cohort was extremely content to have the instructor teach to them, ranking it third among 36 different attitude questions and differing from the oldest cohort $(p<0.001)$ who ranked this factor twentieth.

Secondly, perceptions of equality differed among the cohorts $(\mathrm{F}=6.455 ; \mathrm{p}<0.01)$; the oldest cohort placed little value being seen as an equal within the classroom, a perception that is extremely important to the younger cohorts $(\mathrm{p}<0.01)$. Finally, the attitude around how challenging a learner finds their particular program of study showed a wide variety of responses $(\mathrm{F}=5.506 ; \mathrm{p}<0.01)$. The youngest cohort believed their current program is significantly less challenging to them than the older cohorts ( $\mathrm{p}=0.01)$. Perhaps the challenge faced by the older cohort is due to the length of time after formal studies and the comfort level within the learning environment.

\section{Discussion}

Overall, the variations among age groups were far fewer than was inferred from prior literature. Although a few key areas did have significant differences, no more than $25 \%$ of questions in any particular topic area revealed age-related issues. The majority of distinctions that emerged among age groups centred on social or family pressures of time and money, results that align with the earlier work of both O'Donnell \& Tobbell (2007) and Lundberg (2003). Furthermore, the younger cohorts appear

\section{Table 2}

Barrier Rankings (means with ranking level in parenthesis)

\begin{tabular}{|l|c|c|c|c|}
\hline & Aggregated & 24 and younger & 25 to 29 & 30 and older \\
\hline Time away from my family & $2.65(4)$ & $2.32(4)$ & $3.07(2)$ & $3.03(3)$ \\
\hline Lack of confidence in my abilities & $2.44(5)$ & $2.29(5)$ & $2.30(6)$ & $2.75(6)$ \\
\hline $\begin{array}{l}\text { Concerned about attending school with } \\
\text { younger students }\end{array}$ & $2.17(6)$ & $1.54(10)$ & $2.60(5)$ & $3.03(4)$ \\
\hline $\begin{array}{l}\text { Lack of childcare } \\
\text { Lack of funds for childcare }\end{array}$ & $1.04(14)$ & $0.69(14)$ & $1.30(14)$ & $1.50(12)$ \\
\hline
\end{tabular}




\section{Table 3}

Attitudes and Value (means with ranking level in parenthesis)

\begin{tabular}{|l|c|c|c|c|}
\hline & Aggregated & 24 and younger & 25 to 29 & 30 and older \\
\hline $\begin{array}{l}\text { Time management is important to my } \\
\text { success }\end{array}$ & $4.34(4)$ & $4.25(7)$ & $4.33(6)$ & $4.50(4)$ \\
\hline $\begin{array}{l}\text { It is important for me to be seen as an } \\
\text { equal }\end{array}$ & $4.18(8)$ & $4.25(6)$ & $4.47(4)$ & $3.94(18)$ \\
\hline $\begin{array}{l}\text { The course and program content } \\
\text { challenges me }\end{array}$ & $4.16(11)$ & $3.99(15)$ & $4.40(5)$ & $4.34(6)$ \\
\hline $\begin{array}{l}\text { I am content to have the instructor teach } \\
\text { to me }\end{array}$ & $4.13(12)$ & $4.32(3)$ & $4.13(11)$ & $3.79(20)$ \\
\hline $\begin{array}{l}\text { I feel comfortable expressing myself due } \\
\text { to my past experience or knowledge }\end{array}$ & $3.99(16)$ & $3.87(17)$ & $4.00(16)$ & $4.19(9)$ \\
\hline $\begin{array}{l}\text { My background experience can make a } \\
\text { contribution to class }\end{array}$ & $3.74(20)$ & $3.56(20)$ & $3.90(18)$ & $3.96(17)$ \\
\hline
\end{tabular}

to hold non-traditional views regarding in-class power relationships. This group has a strong desire to be seen as equals. Yet paradoxically, this group also willingly accepts it when the instructor teaches to them, in opposition to the desire to participate from the older cohort. These results support the earlier results of Bamber and Tett (2000). However, beyond all of these differences, the most substantial barriers to post-secondary education among all age groups are funding and monetary issues.

\section{Limitations}

Just as Kimmel and McNeese (2006) acknowledged, we understand that by surveying current students we are, by definition, missing any student who may have had the motivation to return to college for employment training or credential upgrading, but faced barriers that could not be overcome. Furthermore, we acknowledge that the method of distributing surveys through the college email system did not provide the level of response originally hoped for; multiple methods should have been used to engage the students to participate. Despite these limitations, we are hopeful that the results of our work will provide useful insight to faculty and administration within higher education institutions. The demographic range of those sitting in the post-secondary classroom is changing. A better understanding of the motivation and barriers faced by today's students should help increase the opportunities for successful outcomes.

\section{References}

Bamber, J. \& Tett, L. (2000). Transforming the learning experiences of non-traditional students: A perspective from higher education. Studies in Continuing Education, 22(1), 57-75.

Kimmel, S. \& McNeese, M. (2006), Barriers to business education: Motivating adult learners. The Journal of Behavioural and Applied Management, 7(3), 291-303.

Lowy, A. (2007). No problem. Bloomington, IN: Author House.

Lundberg, C.A. (2003). The influence of time: Limitations, faculty, and peer relationships on adult student learning: A causal model. Journal of Higher Education, 665(24). 
O’Donnell, V.L. \& Tobbell, J. (2007). The transition of adult students to higher education: Legitimate peripheral participation in a community of practice? Adult Education Quarterly, 57, 312-328.

Tamburri, R. (2009, April 20). Laid-off workers go back to school, creating challenges for colleges. The Globe or Mail.

\section{Biographies}

William C. Murray is a Ph.D. Candidate (Management) and a faculty member in Hospitality and Tourism Management at NBCC.

Leslie Smith has a M.Ed. and is a faculty member in Hospitality and Tourism Management at NBCC.

Keith Nielson is a student in Hospitality and Tourism Management at NBCC, specializing in Culinary Management. 